\title{
Hashimoto Thyroiditis and Dyslipidemia in Childhood: A Review
}

\author{
Rade Vukovic ${ }^{1,2 *}$, Aleksandra Zeljkovic ${ }^{3}$, Biljana Bufan $^{4}$, Vesna Spasojevic-Kalimanovska ${ }^{3}$, \\ Tatjana Milenkovic ${ }^{1}$ and Jelena Vekic ${ }^{3}$
}

'Department of Pediatric Endocrinology, Mother and Child Healthcare Institute of Serbia "Dr Vukan Cupic", Belgrade, Serbia, ${ }^{2}$ School of Medicine, University of Belgrade, Belgrade, Serbia, ${ }^{3}$ Department of Medical Biochemistry, Faculty of Pharmacy, University of Belgrade, Belgrade, Serbia, ${ }^{4}$ Department of Microbiology and Immunology, Faculty of Pharmacy, University of Belgrade, Belgrade, Serbia

\section{OPEN ACCESS}

Edited by: Mohamad Maghnie, University of Genoa, Italy

Reviewed by:

Giorgio Radetti,

Ospedale di Bolzano, Italy Malgorzata Wasniewska,

University of Messina, Italy

*Correspondence: Rade Vukovic radevukovic9@gmail.com

Specialty section This article was submitted to Pediatric Endocrinology, a section of the journal Frontiers in Endocrinology

Received: 26 October 2019 Accepted: 27 November 2019 Published: 10 December 2019

Citation:

Vukovic R, Zeljkovic A, Bufan B, Spasojevic-Kalimanovska $V$, Milenkovic T and Vekic J (2019) Hashimoto Thyroiditis and Dyslipidemia in Childhood: A Review.

Front. Endocrinol. 10:868 doi: 10.3389/fendo.2019.00868
Hashimoto autoimmune thyroiditis (AIT) is the most common cause of acquired hypothyroidism in the pediatric population. Development of AIT is mediated mainly by cellular immune response directed toward thyroid autoantigens, leading to inflammation and impaired function of thyroid gland. Both thyroid dysfunction and inflammation affect the metabolism of plasma lipoproteins. The alterations in lipid profile worsen with the advancement of hypothyroidism, ranging from discrete changes in euthyroid AIT patients, to atherogenic dyslipidemia in the overt hypothyroidism. In this review, characteristics of dyslipidemia in pediatric AIT patients, and the consequences in respect to the risk for cardiovascular disease (CVD) development are discussed. Additionally, benefit of L-thyroxine treatment on serum lipid profile in pediatric AIT patients is addressed. Finally, potential usefulness of novel lipid biomarkers, such as proprotein convertase subtilisin/kexin type 9 (PCSK9), non-cholesterol sterols, low-density lipoprotein particle size and number, and high-density lipoprotein structure and functionality in AIT patients is also covered. Further longitudinal studies are needed in order to elucidate the long-term cardiovascular outcomes of dyslipidemia in pediatric patients with Hashimoto AIT.

Keywords: Hashimoto autoimmune thyroiditis, children, dyslipidemia, novel lipid biomarkers, L-thyroxine treatment

\section{INTRODUCTION}

Hashimoto autoimmune thyroiditis (AIT) is the most common cause of acquired hypothyroidism in childhood and adolescence. The prevalence of AIT in childhood peaks at early to mid- puberty. Presentation of the disease is rare before the age of 3 years, but there are described cases in infancy, too (1). Female strong preponderance has been reported with female to male ratio up to 3.4:1 (1-3), with high prevalence in patients with Down and Turner syndrome (4). Clinical manifestations of AIT in childhood are extremely diverse, ranging from completely normal, asymptomatic state, to pronounced symptoms of severe thyroid dysfunction.

Thyroid hormones have a broad spectrum of physiological effects on lipoprotein metabolism. As a result, plasma lipid and lipoprotein levels are sensitive to changes in the thyroid hormones concentrations. The alterations in lipid profile accompanying AIT worsen along with the advancement of hypothyroidism, ranging from discrete pro-atherogenic markers in euthyroid AIT, to full-blown dyslipidemia in many patients with the overt hypothyroidism (5-7). Furthermore, autoimmune disease itself has significant impact on lipid profile, as evidenced by a high prevalence of dyslipidemia in patients with autoimmune diseases (8-10), which may account, at least in part, 
to the increased cardiovascular disease (CVD) risk. Thus, it could be regarded as convenient that the efficacy of L-thyroxine (LT4) treatment in the normalization of lipid status is directly proportionate to the degree of thyroid dysfunction, being highest in the overt hypothyroidism $(5,7,11,12)$. However, the waist majority of data linking autoimmune thyroid disease with dyslipidemia were gained from the studies in adults (13), whereas data in pediatric populations are limited. Also, data is scarce regarding the effects of L-T4 treatment on lipid profile in pediatric hypothyroidism, with or without thyroid autoimmunity (14-18).

In this narrative review, we will discuss recent findings regarding the effects of AIT on lipid metabolism and CVD risk, including the impact of L-T4 treatment on dyslipidemia and potential use of novel lipid biomarkers in pediatric patients with AIT.

\section{DEVELOPMENT AND CLINICAL MANIFESTATIONS OF HASHIMOTO'S THYROIDITIS IN CHILDHOOD}

Like other autoimmune diseases, AIT is multifactorial disease caused by complex interplay of genetic $(1,19-26)$, environmental $(21,27-29)$, and hormonal factors $(19,21,30)$, that provoke the inappropriate immune response against thyroid gland. HT is mainly mediated by cellular immune response directed toward thyroid autoantigens, leading to inflammation, fibrosis, and impaired function of thyroid gland $(4,26)$. The first step in pathogenesis is believed to be activation of autoreactive CD4+ $\mathrm{T}$ cells i.e., $\mathrm{T}$ helper (Th) cells specific for thyroid autoantigens. Th cells type 1 (Th1) activate cytotoxic T lymphocytes (CD8+ lymphocytes) and macrophages, which directly destroy thyroid follicular cells (31). Another subset of Th cells with a role in development and progress of chronic inflammation and tissue damage in HT are Th17 cells. Higher proportion of Th17 cells, as well as higher levels of cytokines produced by these cells were found in peripheral blood and thyroid tissue in HT patients compared with healthy controls (32-34). It is also observed that $\mathrm{T}$ regulatory (Treg) cells, cells with immunosuppressive function, accumulate in thyroid tissue of HT patients. However, in these patients Treg cells were found to be dysfunctional (35, 36). B lymphocytes, although representing humoral immunity, are also activated in AIT, producing antibodies against thyroid autoantigens (26). These cells are part of thyroid lymphocyte infiltrate (37) and exert antibody synthesis in the gland $(31,38)$. Autoantibodies are crucial component in AIT pathogenesis, since antibody-dependent cell-mediated cytotoxicity is another and important factor responsible for apoptosis of thyroid follicular cells in this disease $(26,31)$.

Clinical presentation of AIT is best reviewed with respect to the thyroid status, since children with AIT can present as completely euthyroid, with mild subclinical hypothyroidism, severe overt hypothyroidism, or in the state of subclinical or overt hyperthyroidism (Hashitoxicosis) (39-43). Majority of children with AIT are either euthyroid or subclinically hypothyroid at the time of diagnosis $(41,42)$. Euthyroid state, defined by thyroid function tests within normal range, is usually asymptomatic, besides the frequent finding of a goiter $(41,42,44,45)$. Subclinical hypothyroidism in AIT, defined by elevated TSH with normal levels of serum thyroid hormones (fT4 and fT3), is usually classified as mild (TSH $4.5-10 \mathrm{mIU} / \mathrm{l})$ or severe $(\mathrm{TSH}>10$ $\mathrm{mIU} / \mathrm{l})(7,41,46-49)$. Although the very name-"subclinical hypothyroidism" implies that this form of thyroid dysfunction presents merely as a laboratory finding without any signs or symptoms of clinical hypothyroidism besides goiter, these patients actually may present with other clinical and laboratory findings $(7,45,47,50,51)$. Typical clinical signs and symptoms of hypothyroidism have been reported in some children with subclinical hypothyroidism, as well as the improvement of hypothyroidism symptoms scores with L-T4 treatment $(7,47$, 51). Also, untreated long-lasting subclinical hypothyroidism in children has been firmly associated with subtle pro-atherogenic alterations in lipid profile $(7,17,52)$. On the other hand, currently available data indicate that children with untreated longstanding subclinical hypothyroidism have normal linear growth, neurocognitive and behavioral outcomes, and bone health status $(7,47,48,53)$. It should be noted that although the association of obesity and subclinical hypothyroidism is welldocumented, abnormal thyroid function in obese patients seems to be a consequence of obesity, rather than a cause $(47,48)$.

Overt hypothyroidism, defined by elevated TSH with low level of serum fT4, is present in $\sim 20 \%$ of all children with AIT at the time of diagnosis, and the onset of clinical manifestations is usually subtle $(41,42,46)$. Classical signs and symptoms of overt hypothyroidism which may be seen in these children are: goiter, constipation, weight gain, poor growth velocity or short stature, fatigue and somnolence, poor school performance, cold intolerance, dry skin, bradycardia, yellowishpale skin tone with facial puffiness (myxedema), with frequent laboratory findings of anemia and dyslipidemia (41, 42, 46). Adolescents with overt hypothyroidism can also present with delayed or arrested pubertal development, irregular menstrual periods, menometrorrhagia, or amenorrhea in girls $(41,46)$. Rarely, girls with longstanding severe overt hypothyroidism can present with precocious puberty and menstrual bleeding with hyperprolactinaemia and delayed bone age (Van Wyk-Grumbach syndrome) $(42,46,54)$.

Hashitoxicosis, the initial hyperthyroid phase of AIT caused by the release of preformed thyroid hormones from the gland, can be detected in $\sim 10 \%$, and subclinical hypothyroidism in up to $3 \%$ of children with AIT (3943, 55-57). Clinical signs and symptoms of children with hashitoxicosis are those of hyperthyroidism, and cannot be distinguishable can be indistinguishable from Grave's disease: goiter, tachycardia, tremor, weight loss, restlessness, warm moist skin, ophthalmopathy, growth acceleration, delayed, or precocious puberty $(39,41,58)$. Fortunately, this hyperthyroid phase of AIT is transient, usually resolving within several months into euthyroid state, or progressing to permanent hypothyroidism $(41,55,56)$.

Apart from the described symptoms caused by the thyroid dysfunction itself, children with AIT may also have other autoimmune diseases or syndromes, such as celiac disease, 
type 1 diabetes (T1DM), Down's or Turner's syndrome, with corresponding symptoms adding to the overall clinical picture $(42,46)$.

\section{HASHIMOTO THYROIDITIS AND DYSLIPIDEMIA}

In general, subclinical hypothyroidism can slow-down metabolic pathways of cholesterol uptake, synthesis, and secretion, as well as reverse cholesterol transport process and catabolism of triglyceride (TG)-rich lipoproteins (Figure 1) (12, 59, 60). As compared to healthy children, total and low-density lipoprotein cholesterol (LDL-C) levels are commonly elevated, while the level of high-density lipoprotein cholesterol (HDL-C) can be normal or decreased in patients with subclinical hypothyroidism (Table 1). Although some authors reported no differences in serum lipid profile between pediatric patients with subclinical hypothyroidism and controls, the frequency of dyslipidemic children was significantly higher in the patients group (51, 61). The study evaluating children, adolescents and adults with subclinical hypothyroidism suggested that abnormalities in lipid profile are more pronounced in adult patients, as well as in those with severe form of the disease (62). Yet, the impact of the disease severity on lipid profile was not confirmed in later studies in pediatric patients $(61,63)$.

The hallmark of subclinical hypothyroidism-related dyslipidemia is reduced synthesis of liver LDL receptors and the mechanisms behind this effect have been extensively studied and explained. Emerging evidence suggests that the levels of circulating proprotein convertase subtilisin/kexin type 9 (PCSK9), a serin-protease responsible for downregulation of liver LDL receptors, is also increased in subclinical hypothyroidism (64), paving the way for innovative lipid-lowering therapy in this category of patients (5). However, data on PCSK9 in children are

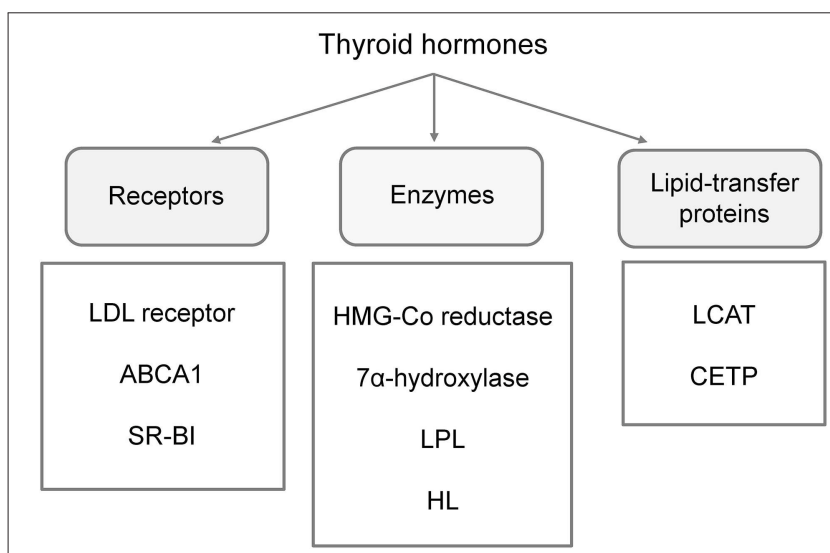

FIGURE 1 | Main effector molecules involved in alterations of lipoprotein metabolism driven by thyroid hormones. LDL, low-density lipoprotein; ABCA1, ATP binding cassette subfamily A member 1; SR-BI, scavenger receptor class B type 1; LPL, lipoprotein-lipase; HL, hepatic lipase; LCAT, lecithin:cholesterol acyltransferase; CETP, cholesteryl-ester transfer protein. sparse and the studies examining efficacy, safety, and tolerability of PCSK9 inhibitors in pediatric patients are underway (65).

Body cholesterol pool is maintained by delicate balance between the processes of cholesterol synthesis, absorption, and biliary secretion, all of which can be affected even by subtle alterations in thyroid hormones levels (60). Plasma noncholesterol sterols, including cholesterol precursors and plant sterols, are validated biomarkers of cholesterol biosynthesis and intestinal absorption efficiency (66). The results of a small study by Matysik et al. (67) suggested that the levels of plasma non-cholesterol sterols could serve as indicators of disrupted cholesterol homeostasis in patients with hyper- and hypothyroidism. Recently, plasma profile of non-cholesterol sterols from birth to 15 years of age was characterized in pediatric population without dyslipidemia (68). These data could form a solid base for future evaluation of the extent of cholesterol synthesis and absorption alterations in children and adolescents with AIT.

The lack of thyroid hormones is associated with reduced clearance of TG-rich particles, due to attenuated lipoproteinlipase (LPL) and hepatic lipase (HL) activities, and increased production of very-low density lipoprotein (VLDL) particles (5). Hence, apart from the impact on LDL-C level, thyroid dysfunction may affect qualitative characteristics and functional properties of LDL particles. Namely, hypertriglyceridemia is intimately linked to the increased production of small, dense LDL particles (69). Bearing in mind that thyroid hormones may protect LDL particles from oxidation (70), and the fact that small, dense LDL particles are prone to oxidative modifications (69), there is increased potential for adverse modification of LDL particles in hypothyroid state. Indeed, increased small, dense LDL, and oxidized LDL particles were recently reported in normolipidemic adult patients with hypothyroidism (71). These data clearly demonstrated the usefulness of advanced lipid testing for identification of the patients with high CVD risk, which should be further confirmed in pediatric patients with both subclinical and overt thyroid dysfunction.

In contrast to firm scientific and clinical evidence which consistently points to elevated LDL-C concentrations in patients with hypothyroidism, data regarding HDL-C are not homogenous. As it has been presented in Table 1, HDL-C levels were decreased or unchanged in hypothyroid states. Interpretation of data and drawing of conclusions is particularly complicated in pediatric population, since most of the data regarding the association of HDL and thyroid status is derived from studies in adults. It is also noteworthy that studies analyzing HDL-C concentration in children with hypothyroidism were conducted in smaller cohorts, which might affect the reliability of the obtained results. Therefore, larger studies with prospective design are needed to resolve this issue.

However, a contemporary approach to HDL's clinical significance might put aside these conflicting results concerning HDL-C levels in hypothyroid subjects, since another question is considered as even more important in modern research and clinical practice. Namely, due to complex structure and numerous functions of HDL, it is nowadays accepted that quality of this lipoprotein's particles is more significant than their 
TABLE 1 | Lipid profile of pediatric patients with subclinical hypothyroidism.

\begin{tabular}{|c|c|c|c|c|}
\hline Authors & $N$ & Age, years & Alterations of lipid profile & References \\
\hline Paoli-Valeri et al. (2005) & 17 & $4.3 \pm 1.0$ & $\downarrow$ HDL-C; $\leftrightarrow \mathrm{TC} ; \leftrightarrow$ LDL-C; $\leftrightarrow$ TG; $\leftrightarrow$ TC/HDL-C; $\leftrightarrow$ LDL-C/HDL-C & $(14)$ \\
\hline Cerbone et al. (2014) & 49 & $8.5 \pm 0.5$ & 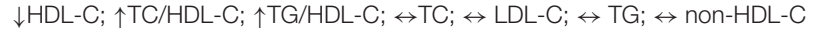 & $(17)$ \\
\hline Dahl et al. (2018) & 228 & $13.3 \pm 4.2$ & $\uparrow T C ; \uparrow n o n-H D L-C ; \leftrightarrow H D L-C$ & $(18)$ \\
\hline Catli et al. (2014) & 27 & $10(6.9)^{\star}$ & $\leftrightarrow \mathrm{TC} ; \leftrightarrow \mathrm{LDL}-\mathrm{C} ; \leftrightarrow \mathrm{HDL}-\mathrm{C} ; \leftrightarrow \mathrm{TG}$ & (51) \\
\hline Cerbone et al. (2016) & 39 & $9.2 \pm 3.6$ & 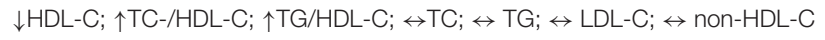 & $(52)$ \\
\hline Unal et al. (2017) & 38 & $8.1 \pm 3.6$ & $\uparrow T C ; \uparrow L D L-C ; \uparrow L D L-C / H D L-C ; \uparrow T C / H D L-C ; \leftrightarrow$ HDL-C; $\leftrightarrow$ TG & $(61)$ \\
\hline Marwaha et al. (2011) & $280 / 35^{\#}$ & $12.8 \pm 2.8$ & $\leftrightarrow / \downarrow H D L-C ; \leftrightarrow / \leftrightarrow T C ; \leftrightarrow / \uparrow T G ; \leftrightarrow / \uparrow ~ L D L-C$ & $(62)$ \\
\hline Isguven et al. (2016) & 66 & $14.4 \pm 2.4$ & $\uparrow T C ; \uparrow L D L-C ; \leftrightarrow$ TG; $\leftrightarrow$ HDL-C & (63) \\
\hline
\end{tabular}

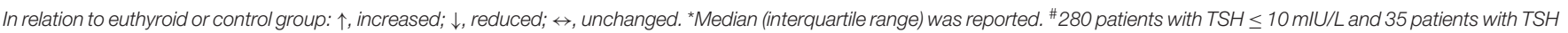

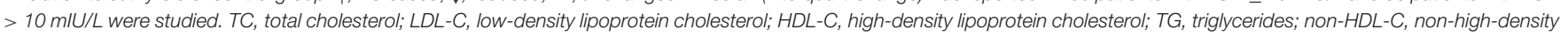
lipoprotein cholesterol.

cholesterol content (72). As precisely summarized in a review by Triolo et al. (73), functional properties of HDL could be grouped in four essential categories: reverse cholesterol transport, antioxidative, anti-inflammatory, and vasodilatatory activities. It has also been demonstrated that alterations in HDL structure affect its functionality. In addition, it is now clear that both HDL structure and functions can be easily modified if changes occur in their vascular environment (74). Therefore, several new aspects should be considered regarding HDL in patients with AIT, including the impact of subclinical or overt hypothyroidism on HDL's quality, as well as the influence of pro-inflammatory and pro-oxidative environment on these particles. Providing answers on these questions might have significant implications for interpretation of CVD risk in AIT patients, especially those of young age, considering their long-term exposure to possible detrimental factors (Figure 2).

Changes of HDL's structure and function in relation to thyroid hormones status are largely unexplored. However, a recent study has shown that both cholesterol efflux and activity of HDL-associated enzyme paraoxonase 1 (PON1) are decreased in patients with overt hypothyroidism (75), thus implicating diminishing of HDL functionality. Several reasons could be responsible for such findings. Namely, studies involving human subjects and animal models have demonstrated that hypothyroidism is associated with decreased activities of cholesteryl-ester transfer protein (CETP), lecithin:cholesterol acyltransferase (LCAT), and HL $(76,77)$. Having in mind that these enzymes are key regulators of HDL metabolism, changes in HDL structure and consequently function should be expected. Indeed, a higher prevalence of larger HDL 2 subclasses was found in subjects with hypothyroidism in a study by Tan et al. (76). Larger HDL particles are generally considered as highly atheroprotective, but, as it has been already mentioned, novel data (75) suggest that functionality of HDL particles in hypothyroidism is compromised.

The next aspect that should be considered is the impact of inflammation on HDL particles. So far, changes in both HDL-C level and HDL structure have been reported in several autoimmune diseases (78). It is also noteworthy that AIT is the most frequent co-morbidity of pediatric patients with T1DM
(79). In our recent study, we analyzed lipid and lipoprotein subclasses profile in pediatric T1DM patients with and without co-existing autoimmune diseases and found that those with associated Hashimoto AIT had more profound dyslipidemia (80). Generally speaking, HDL possesses strong anti-inflammatory properties, but it has been demonstrated that pro-inflammatory environment can diminish its protective capacity (78). Being an autoimmune disease, Hashimoto thyroiditis is characterized by chronic inflammation (81). Many components of inflammation are shown to affect HDL particles. Previous researches pointed toward serum amyloid A (SAA), which is abundantly produced in inflammatory states and is capable to replace apolipoprotein AI (apo-AI) on HDL particles, thereby diminishing their anti-inflammatory properties and, paradoxically, turning them into inflammatory agents (78). Moreover, it has been shown that activity of LCAT is reduced (82) as a consequence of inflammation and this can compromise maturation and normal function of HDL particles. In addition, a decrease in CETP mass and activity was also observed in pro-inflammatory conditions $(82,83)$, although, it was suggested that this could be an adaptive mechanism aimed to prevent massive HDL-C reduction, which is driven by other factors (83). It should also be mentioned that PON1 levels and activity are decreased during inflammation, thereby diminishing antioxidative properties of HDL (84). As for Hashimoto AIT, it has been shown that PON1 level is decreased in these patients $(85,86)$.

Finally, HDL is a major carrier of sphingosine-1-phosphate (S1P) and evidence suggests that the interaction of S1P with HDL has significant impact on S1P activity $(87,88)$. S1P is wellknown mediator of immune response (89) and recently it has been demonstrated that S1P participates in the development of Hashimoto AIT through its interaction with S1P receptor 1 (90). Yet, whether structural changes of HDL participate in modification of S1P activity in AIT is still to be revealed. Furthermore, the impact of these interactions on increase of CVD risk in Hashimoto AIT, especially in pediatric population, needs to be evaluated.

Before making any conclusions regarding lipid status in AIT, one should be aware that autoimmune disorders frequently aggregate in the same patient. A recent review (91) has shown 


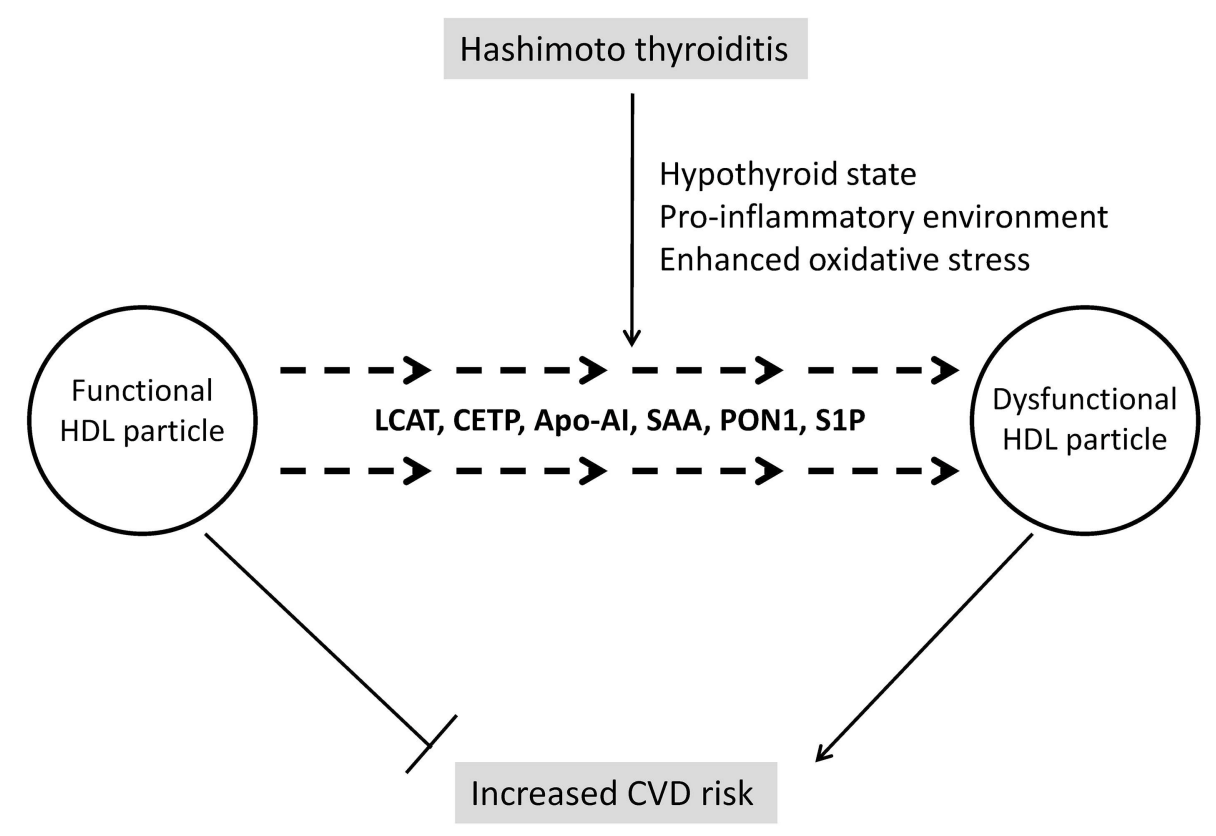

FIGURE 2 | Changes of HDL structure and functionality in Hashimoto thyroiditis. LCAT, lecithin:cholesterol acyltransferase; Apo-Al, apolipoprotein A-l; SAA, serum amyloid A; PON1, paraoxonase 1; S1P, sphingosine-1-phosphate.

that various autoimmune comorbidities are associated with AIT in an age-dependent manner. Namely, studies reported that frequency of co-existing autoimmune diseases in children with AIT ranges between 6.6 and $58.2 \%$, wherein celiac disease and T1DM are the most frequent comorbidities (91). Thus, possible contribution of other co-existing autoimmune diseases on lipid profile in AIT should not be neglected.

It is known that T1DM is associated with alterations of serum lipid profile. Semova et al. (92) recently demonstrated decreased cholesterol synthesis and increased cholesterol absorption, with concomitant changes in TC, LDL-C, and HDL-C levels in young patients with T1DM, when compared to age-matched healthy individuals. Moreover, it has been suggested that both structural and functional alterations affect HDL particles in T1DM (93). Similarly, it has been shown that patients with celiac disease exhibit changes in lipid profile, especially decreased HDL-C concentration (94). Yet, it is noteworthy that independent effects of co-existing autoimmune diseases on serum lipids are rarely evaluated. However, it has been reported that LDL-C and TG levels are higher in children with concomitant presence of T1DM and celiac disease, when compared to children with T1DM alone (95). Moreover, lower HDL-C levels were found in children with T1DM if celiac disease was co-existing (96). Also, our own results demonstrated that the prevalence of dyslipidemia was higher in pediatric T1DM patients if celiac disease or AIT were concomitantly present (80). Summarizing all mentioned findings, eventual co-existence of other autoimmune diseases should be taken into account for comprehensive evaluation of dyslipidemia in AIT. Further studies are needed to fulfill a gap in current understanding of mechanisms by which polyautoimmunity is involved in development of lipid disorders.

\section{EFFECTS OF L-THYROXINE TREATMENT ON LIPID STATUS IN HASHIMOTO'S AIT}

Most of the known data regarding the beneficial effects of L-T4 treatment on lipid profile is derived from studies in adults with overt or subclinical hypothyroidism (12, 75, 97-102). Among the recent studies, Minarikova et al. demonstrated significant improvements of total cholesterol (TC), LDL-C, TG, apoB, atherogenic index of plasma, and LDL subclasses following L-T4 substitution treatment in 40 newly-diagnosed overt hypothyroidism patients with AIT (103). Uniquely designed study of 27 adult patients who underwent total thyroidectomy and radioactive iodine treatment for differentiated thyroid carcinoma, revealed that dynamic changes in thyroid function are associated with corresponding dynamic changes of the lipid profile and HDL function (75). Compared to the baseline levels (on L-T4 treatment), when patients entered the overt hypothyroid state (TSH > $30 \mathrm{mU} / \mathrm{L}$ after 4 weeks of LT4 withdrawal), the levels of TC, TG, LDL-C, apoA-I, and apoB significantly increased, and then again recovered to the baseline levels after 3 months, following the reinstitution of L-T4 treatment. The levels of HDL-C increased during the overt hypothyroid state, with impairment of function (evaluated by cholesterol efflux capacity and PON1 activity), and these changes persisted despite restoration of thyroid hormone levels. It could not be concluded if impaired HDL-C function would also improve after a longer period of follow-up (75).

Results from studies in the adult population also indicate that L-T4 treatment could result in lowering of TPO-Ab levels in patients with AIT $(104,105)$. This could also potentially lead to the improvement of the lipid profile, having in mind that thyroid 
autoimmunity with higher TPO-Ab levels is associated with an unfavorable lipid profile irrespective of thyroid function, in both children and adults $(13,63,80,106,107)$.

Subclinical hypothyroidism in children, with a prevalence of $2-9 \%$, is generally considered a benign condition with a significant chance of remission, however, findings of subtle proatherogenic abnormalities in these children highlights the lack of consensus regarding treatment criteria $(7,17,49,52,53,108-$ 110). Treatment with L-T4, which was usually recommended only in children with goiter, hypothyroidism symptoms or TSH levels $>10 \mathrm{mU} / \mathrm{L}$, is now being recommended by some experts for treatment of mild subclinical hypothyroidism in cases of: positive TPO-Ab, concomitant celiac disease, TSH $>8 \mathrm{mU} / \mathrm{L}$ in two repeated measurements, gradually increasing TSH levels, hyperlipidemia and younger patient age $(7,47,49,52,53,109)$.

Although the association of thyroid function with atherogenic alterations in lipid profile has been well-documented in children, data is scarce regarding the effects of L-T4 treatment in pediatric hypothyroidism, with or without thyroid autoimmunity (14-18). Dorr et al. observed a decrease of thyroid volume in 25 euthyroid children with Hashimoto's thyroiditis with L-T4 treatment, while changes in lipids were not evaluated (44). Another study also showed reduction of goiter with L-T4 treatment especially in cases of overt hypothyroid, but also in $\mathrm{SH}$ and euthyroid children with AIT (45).

Among the very few studies evaluating the effects of L-T4 treatment in children with subclinical hypothyroidism, only two studies investigated changes in the lipid profile $(51,52,108,111$, 112). In a prospective study by Catli et al., 27 children (median age of 10 years) with subclinical hypothyroidism were treated with L-T4 until achievement of euthyroid state plus 6 months and then compared with euthyroid healthy control group. Seven (26\%) of these patients with SH had AIT. Although improvement in the hypothyroidism symptoms score was associated with L-T4 treatment, no significant differences were observed regarding TC, TG, HDL-C, and LDL-C (51). The absence of significant findings could be attributed to the relatively short duration of follow-up as well as low number of patients enrolled. On the other hand, a prospective case-control study by Cerbone et al. discovered significant effects of 2 years of L-T4 treatment on pro-atherogenic markers in children with mild (TSH 4.5-10.0 mU/L) idiopathic subclinical hypothyroidism (52). A total of 39 children (mean age 9.2 years) with mild idiopathic subclinical hypothyroidism were compared with healthy controls. However, in this study patients with detectable TPO-Ab, Tg-Ab, or abnormal thyroid echogenicity on ultrasound were excluded from the study. Mean HDL-C levels were lower, with higher TG/HDL-C ratio and atherogenic index (TC/HDL-C), in subclinical hypothyroidism subjects compared with controls. After 2 years of L-T4 treatment, these parameters improved significantly in the SH group, so no more significant differences between subclinical hypothyroidism subjects and controls were observed. It was concluded that 2 years of L-T4 treatment resulted in an improvement of many lipid abnormalities in children with mild idiopathic subclinical hypothyroidism (52). However, having in mind that patients with AIT were excluded from this study, results should be interpreted with caution in the context of pediatric hypothyroidism caused by AIT. Further studies are needed to evaluate the metabolic effects of L-T4 treatment in hypothyroid children with AIT, compared with treated non-autoimmune hypothyroid children and not treated healthy controls.

\section{IMPLICATIONS FOR CARDIOVASCULAR PREVENTION AND FUTURE DIRECTIONS}

Dyslipidemia and increased carotid intima media thickness (cIMT), a reliable indicator of subclinical atherosclerosis, was recently documented in pediatric patients with Hashimoto thyroiditis $(61,63)$, suggesting the importance of regular evaluation of cardiovascular risk factors in children with AIT (Figure 3). In recent years, the role of cholesterol in the development of CVD has been challenged. In particular, the main controversy was centered on the impact of dietary fats on cardiovascular risk. According to a recent metaanalysis by de Souza et al. (113), the intake of saturated fatty acids was not associated with a higher cardiovascular risk. Similarly, data from randomized controlled trials shows that the replacement of saturated with polyunsaturated fatty acids might reduce serum cholesterol levels, but does not decrease the risk from all-cause or mortality due to coronary heart disease $(114,115)$. Nevertheless, a panel of experts from the European Atherosclerosis Society recently issued a Consensus Statement, supported by the evidence from genetic, prospective epidemiologic studies, Mendelian randomization studies and randomized trials evaluating lipid-lowering therapies, that high LDL-C is a causal factor in the pathophysiology of CVD and should remain the main therapeutic target (116).

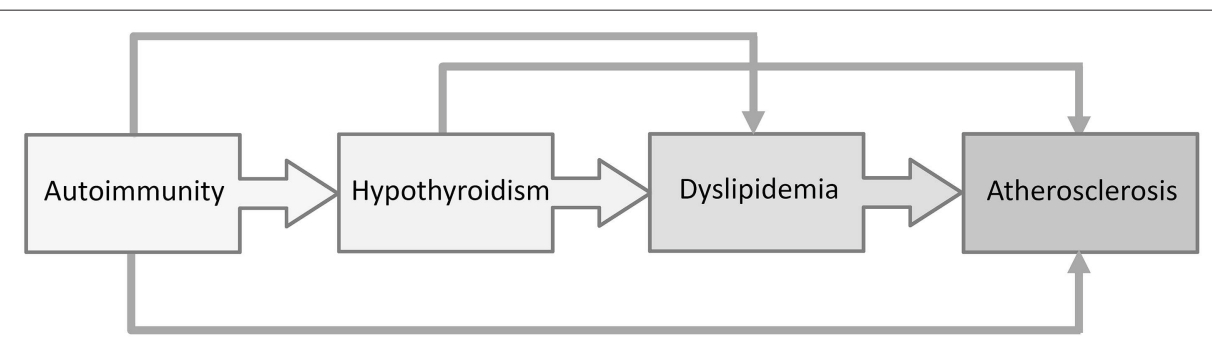

FIGURE 3 | The interplay between Hashimoto thyroiditis, dyslipidemia, and atherosclerosis. 
Although LDL-C level remains primary target for CVD prevention, advanced lipid testing could be advised to reveal hidden cardiovascular risk. In this context, lipoprotein particle size, number and subclasses distribution, HDL lipidome, proteome, and functionality testing may provide valuable information beyond LDL and HDL cholesterol levels. Regarding alterations in metabolism of TG-rich lipoproteins, it can be easily assessed by calculation of non-HDL-C level, as it was recently recommended by expert lipidologists (117). To date, increased PCSK9 levels and its impact on dyslipidema has been reported in the most common autoimmune disease in childhood, T1DM (118), and future studies in pediatric Hashimoto thyroiditis are warranted.

Another important aspect in addressing the link between subclinical hypothyroidism and dyslipidemia is related to the laboratory assessment and interpretation of TSH levels. As stated previously, the definition of subclinical hypothyroidism relies on a mildly elevated serum TSH concentration, which is associated with normal T4 or fT4 levels. According to the guidelines of European Thyroid Association for the management of subclinical hypothyroidism in children, appropriate diagnosis of subclinical hypothyroidism in pediatric patients requires adequate age-adjusted reference ranges for TSH and thyroid hormones is mandatory (119). To date, numerous studies have been performed to define reference range of thyroid hormones in pediatric population, and some of them stratified results according to sex (120-122). Yet, there is still no consensus regarding this issue. Onsesveren et al. (123) recently performed a systematic review of published reference ranges for TSH and fT4 in children and demonstrated substantial differences among studies. For instance, the upper reference limit of TSH ranged between 2.36 and $6.57 \mathrm{mU} / \mathrm{L}$ (123). The difference among published reference values could be a consequence of age, gender, and demographic characteristics of included populations, including lifestyle, iodine, and selenium status (120) and/or different assays employed for the laboratory measurements of thyroid hormones. As previously acknowledged by the National Academy of Clinical Biochemistry, serum TSH level has high biological variability, due to short half-life and diurnal variation (124). Also, as a consequence of improved sensitivity and specificity of the methods for TSH determination, the upper reference limit for TSH decreased over time. Finally, it should not be neglected that thyroid hormones circulate bound to plasma

\section{REFERENCES}

1. Cappa M, Bizzarri C, Crea F. Autoimmune thyroid diseases in children. J Thyroid Res. (2010) 2011:675703. doi: 10.4061/2011/6 75703

2. Hunter I, Greene SA, MacDonald TM, Morris AD. Prevalence and aetiology of hypothyroidism in the young. Arch Dis Child. (2000) 83:207-10. doi: 10.1136/adc.83.3.207

3. Desai MP, Karandikar S. Autoimmune thyroid disease in childhood: a study of children and their families. Indian Pediatr. (1999) 36:659-68.

4. Wassner AJ. Pediatric hypothyroidism: diagnosis and treatment. Paediatr Drugs. (2017) 19:291-301. doi: 10.1007/s40272-017-0238-0 proteins, and their biological action is exerted by the fraction $(0.02-0.1 \%)$ of unbound or "free" form (4). Hence, the direct fT4 assays may be inaccurate in patients with severe systemic illness or abnormalities of protein binding, so caution is needed when interpreting such tests in this setting (4).

Unlike other forms of subclinical hypothyroidism in childhood, Hashimoto AIT is characterized by an increased likelihood for progression to overt hypothyroidism (47). Long-term cardiovascular outcomes in pediatric patients with Hashimoto thyroiditis are largely unknown due to lack of longitudinal prospective studies. In addition, clinical studies aimed to address benefit of L-T4 administration on future cardiovascular health are required. Available data indicate that statins also have certain immunomodulatory properties (125). Hence, the impact on conventional dyslipidemia treatment on thyroid autoimmunity should be explored in the future.

\section{CONCLUSIONS}

Available evidence suggests that AIT is associated with profound changes of lipid profile, which are driven not only by a decrease in thyroid hormones, but also by chronic inflammation and disturbed redox balance. In light of the current scientific data, novel biomarkers of altered lipoprotein metabolism might provide more complete information regarding lipid profile of Hashimoto AIT patients and subsequent cardiovascular risk. However, lack of reliable results in pediatric AIT patients urges the need for more comprehensive studies aimed to explore characteristics of dyslipidemia in children with Hashimoto AIT and implications for their future cardiovascular health.

\section{AUTHOR CONTRIBUTIONS}

All authors listed have made a substantial, direct and intellectual contribution to the work, and approved it for publication.

\section{FUNDING}

The authors from the Department of Medical Biochemistry, Faculty of Pharmacy are financially supported by a grant from the Ministry of Education, Science and Technological Development, Republic of Serbia (Project No. 175035). 
9. Bag-Ozbek A, Giles JT. Inflammation, adiposity, and atherogenic dyslipidemia in rheumatoid arthritis: is there a paradoxical relationship? Curr Allergy Asthma Rep. (2015) 15:497. doi: 10.1007/s11882-014-0497-6

10. Tselios K, Koumaras C, Gladman DD, Urowitz MB. Dyslipidemia in systemic lupus erythematosus: just another comorbidity? Semin Arthritis Rheum. (2016) 45:604-10. doi: 10.1016/j.semarthrit.2015.10.010

11. O’Brien T, Dinneen SF, O'Brien PC, Palumbo PJ. Hyperlipidemia in patients with primary and secondary hypothyroidism. Mayo Clin Proc. (1993) 68:860-6. doi: 10.1016/S0025-6196(12)60694-6

12. Rizos CV, Elisaf MS, Liberopoulos EN. Effects of thyroid dysfunction on lipid profile. Open Cardiovasc Med J. (2011) 5:76-84. doi: 10.2174/1874192401105010076

13. Tamer G, Mert M, Tamer I, Mesci B, Kilic D, Arik S. Effects of thyroid autoimmunity on abdominal obesity and hyperlipidaemia. Endokrynol Pol. (2011) 62:421-8.

14. Paoli-Valeri M, Guzman M, Jimenez-Lopez V, Arias-Ferreira A, Briceno-Fernandez M, Arata-Bellabarba G. Atherogenic lipid profile in children with subclinical hypothyroidism. An Pediatr. (2005) 62:128-34. doi: $10.1157 / 13071309$

15. Witte T, Ittermann T, Thamm M, Riblet NB, Volzke H. Association between serum thyroid-stimulating hormone levels and serum lipids in children and adolescents: a population-based study of german youth. J Clin Endocrinol Metab. (2015) 100:2090-7. doi: 10.1210/jc.2014-4466

16. Zhang J, Jiang R, Li L, Li P, Li X, Wang Z, et al. Serum thyrotropin is positively correlated with the metabolic syndrome components of obesity and dyslipidemia in chinese adolescents. Int J Endocrinol. (2014) 2014:289503. doi: 10.1155/2014/289503

17. Cerbone M, Capalbo D, Wasniewska M, Mattace Raso G, Alfano S, Meli R, et al. Cardiovascular risk factors in children with long-standing untreated idiopathic subclinical hypothyroidism. J Clin Endocrinol Metab. (2014) 99:2697-703. doi: 10.1210/jc.2014-1761

18. Dahl AR, Iqbal AM, Lteif AN, Pittock ST, Tebben PJ, Kumar S. Mild subclinical hypothyroidism is associated with paediatric dyslipidaemia. Clin Endocrinol. (2018) 89:330-5. doi: 10.1111/cen.13752

19. Weetman AP. The immunopathogenesis of chronic autoimmune thyroiditis one century after hashimoto. Eur Thyroid J. (2013) 1:243-50. doi: $10.1159 / 000343834$

20. Brown R, Francis GL. Autoimmune thyroid disorders. J Thyroid Res. (2011) 2011:432890. doi: 10.4061/2011/432890

21. Dong YH, Fu DG. Autoimmune thyroid disease: mechanism, genetics and current knowledge. Eur Rev Med Pharmacol Sci. (2014) 18:3611-8.

22. Menconi F, Monti MC, Greenberg DA, Oashi T, Osman R, Davies TF, et al. Molecular amino acid signatures in the MHC class II peptide-binding pocket predispose to autoimmune thyroiditis in humans and in mice. Proc Natl Acad Sci USA. (2008) 105:14034-9. doi: 10.1073/pnas.0806584105

23. Zeitlin AA, Heward JM, Newby PR, Carr-Smith JD, Franklyn JA, Gough SC, et al. Analysis of HLA class II genes in Hashimoto's thyroiditis reveals differences compared to Graves' disease. Genes Immun. (2008) 9:358-63. doi: 10.1038 /gene.2008.26

24. Jacobson EM, Tomer Y. The CD40, CTLA-4, thyroglobulin, TSH receptor, and PTPN22 gene quintet and its contribution to thyroid autoimmunity: back to the future. J Autoimmun. (2007) 28:85-98. doi: 10.1016/j.jaut.2007.02.006

25. Tomer Y. Genetic susceptibility to autoimmune thyroid disease: past, present, and future. Thyroid. (2010) 20:715-25. doi: 10.1089/thy.2010.1644

26. Rydzewska M, Jaromin M, Pasierowska IE, Stozek K, Bossowski A. Role of the $\mathrm{T}$ and $\mathrm{B}$ lymphocytes in pathogenesis of autoimmune thyroid diseases. Thyroid Res. (2018) 11:2. doi: 10.1186/s13044-018-0046-9

27. Cogni G, Chiovato L. An overview of the pathogenesis of thyroid autoimmunity. Hormones. (2013) 12:19-29. doi: 10.1007/BF03401283

28. Brent GA. Environmental exposures and autoimmune thyroid disease. Thyroid. (2010) 20:755-61. doi: 10.1089/thy.2010.1636

29. Eschler DC, Hasham A, Tomer Y. Cutting edge: the etiology of autoimmune thyroid diseases. Clin Rev Allergy Immunol. (2011) 41:190-7. doi: $10.1007 /$ s12016-010-8245-8

30. Effraimidis G, Wiersinga WM. Mechanisms in endocrinology: autoimmune thyroid disease: old and new players. Eur J Endocrinol. (2014) 170:R241-52. doi: 10.1530/EJE-14-0047
31. Pyzik A, Grywalska E, Matyjaszek-Matuszek B, Rolinski J. Immune disorders in Hashimoto's thyroiditis: what do we know so far? J Immunol Res. (2015) 2015:979167. doi: 10.1155/2015/979167

32. Qin Q, Liu P, Liu L, Wang R, Yan N, Yang J, et al. The increased but nonpredominant expression of Th17- and Th1-specific cytokines in Hashimoto's thyroiditis but not in Graves' disease. Braz J Med Biol Res. (2012) 45:1202-8. doi: 10.1590/S0100-879X2012007500168

33. Li D, Cai W, Gu R, Zhang Y, Zhang H, Tang K, et al. Th17 cell plays a role in the pathogenesis of Hashimoto's thyroiditis in patients. Clin Immunol. (2013) 149:411-20. doi: 10.1016/j.clim.2013.10.001

34. Gonzalez-Amaro R, Marazuela M. T regulatory (Treg) and T helper 17 (Th17) lymphocytes in thyroid autoimmunity. Endocrine. (2016) 52:30-8. doi: 10.1007/s12020-015-0759-7

35. Mao C, Wang S, Xiao Y, Xu J, Jiang Q, Jin M, et al. Impairment of regulatory capacity of $\mathrm{CD} 4+\mathrm{CD} 25+$ regulatory $\mathrm{T}$ cells mediated by dendritic cell polarization and hyperthyroidism in Graves' disease. J Immunol. (2011) 186:4734-43. doi: 10.4049/jimmunol.0904135

36. Glick AB, Wodzinski A, Fu P, Levine AD, Wald DN. Impairment of regulatory T-cell function in autoimmune thyroid disease. Thyroid. (2013) 23:871-8. doi: 10.1089/thy.2012.0514

37. Ben-Skowronek I, Szewczyk L, Kulik-Rechberger B, Korobowicz E. The differences in T and B cell subsets in thyroid of children with Graves' disease and Hashimoto's thyroiditis. World J Pediatr. (2013) 9:245-50. doi: 10.1007/s12519-013-0398-0

38. Ramos-Levi AM, Marazuela M. Pathogenesis of thyroid autoimmune disease: the role of cellular mechanisms. Endocrinol Nutr. (2016) 63:421-9. doi: $10.1016 /$ j.endonu.2016.04.003

39. Wasniewska M, Corrias A, Salerno M, Lombardo F, Aversa T, Mussa A, et al. Outcomes of children with hashitoxicosis. Horm Res Paediatr. (2012) 77:36-40. doi: 10.1159/000334640

40. Brown RS. Autoimmune thyroiditis in childhood. J Clin Res Pediatr Endocrinol. (2013) 5 (Suppl 1):45-9. doi: 10.4274/Jcrpe.855

41. Caturegli P, De Remigis A, Rose NR. Hashimoto thyroiditis: clinical and diagnostic criteria. Autoimmun Rev. (2014) 13:391-7. doi: 10.1016/j.autrev.2014.01.007

42. Diaz A, Lipman Diaz EG. Hypothyroidism. Pediatr Rev. (2014) 35:336-47; quiz 48-9. doi: 10.1542/pir.35-8-336

43. Aversa T, Valenzise M, Corrias A, Salerno M, Mussa A, Capalbo D, et al. Subclinical hyperthyroidism when presenting as initial manifestation of juvenile Hashimoto's thyroiditis: first report on its natural history. $J$ Endocrinol Invest. (2014) 37:303-8. doi: 10.1007/s40618-014-0054-0

44. Dorr HG, Bettendorf M, Binder G, Karges B, Kneppo C, Schmidt H, et al. Levothyroxine treatment of euthyroid children with autoimmune hashimoto thyroiditis: results of a multicenter, randomized, controlled trial. Horm Res Paediatr. (2015) 84:266-74. doi: 10.1159/000437140

45. Svensson J, Ericsson UB, Nilsson P, Olsson C, Jonsson B, Lindberg B, et al. Levothyroxine treatment reduces thyroid size in children and adolescents with chronic autoimmune thyroiditis. J Clin Endocrinol Metab. (2006) 91:1729-34. doi: 10.1210/jc.2005-2400

46. Counts D, Varma SK. Hypothyroidism in children. Pediatr Rev. (2009) 30:251-8. doi: 10.1542/pir.30-7-251

47. Salerno M, Capalbo D, Cerbone $M$, De Luca F. Subclinical hypothyroidism in childhood - current knowledge and open issues. Nat Rev Endocrinol. (2016) 12:734-46. doi: 10.1038/nrendo.2 016.100

48. Gallizzi R, Crisafulli C, Aversa T, Salzano G, De Luca F, Valenzise M, et al. Subclinical hypothyroidism in children: is it always subclinical? Ital J Pediatr. (2018) 44:25. doi: 10.1186/s13052-018-0462-4

49. Crisafulli G, Aversa T, Zirilli G, Pajno GB, Corica D, De Luca F, et al. Subclinical hypothyroidism in children: when a replacement hormonal treatment might be advisable. Front Endocrinol. (2019) 10:109. doi: 10.3389/fendo.2019.00109

50. Cooper DS, Biondi B. Subclinical thyroid disease. Lancet. (2012) 379:114254. doi: 10.1016/S0140-6736(11)60276-6

51. Catli G, Anik A, Unver Tuhan H, Bober E, Abaci A. The effect of L-thyroxine treatment on hypothyroid symptom scores and lipid profile in children with subclinical hypothyroidism. J Clin Res Pediatr Endocrinol. (2014) 6:238-44. doi: $10.4274 /$ jcrpe. 1594 
52. Cerbone M, Capalbo D, Wasniewska M, Alfano S, Mattace Raso G, Oliviero $\mathrm{U}$, et al. Effects of L-thyroxine treatment on early markers of atherosclerotic disease in children with subclinical hypothyroidism. Eur J Endocrinol. (2016) 175:11-9. doi: 10.1530/EJE-15-0833

53. Cerbone M, Bravaccio C, Capalbo D, Polizzi M, Wasniewska M, Cioffi D, et al. Linear growth and intellectual outcome in children with long-term idiopathic subclinical hypothyroidism. Eur J Endocrinol. (2011) 164:591-7. doi: 10.1530/EJE-10-0979

54. Rastogi A, Bhadada SK, Bhansali A. An unusual presentation of a usual disorder: Van Wyk-Grumbach syndrome. Indian J Endocrinol Metab. (2011) 15(Suppl 2):S141-3. doi: 10.4103/2230-8210.83356

55. Shahbaz A, Aziz K, Umair M, Sachmechi I. Prolonged duration of hashitoxicosis in a patient with Hashimoto's thyroiditis: a case report and review of literature. Cureus. (2018) 10:e2804. doi: 10.7759/cureus.2804

56. Nabhan ZM, Kreher NC, Eugster EA. Hashitoxicosis in children: clinical features and natural history. J Pediatr. (2005) 146:533-6. doi: $10.1016 /$ j.jpeds.2004.10.070

57. Wasniewska M, Corrias A, Salerno M, Mussa A, Capalbo D, Messina MF, et al. Thyroid function patterns at Hashimoto's thyroiditis presentation in childhood and adolescence are mainly conditioned by patients' age. Horm Res Paediatr. (2012) 78:232-6. doi: 10.1159/000343815

58. Hanley P, Lord K, Bauer AJ. Thyroid disorders in children and adolescents: a review. JAMA Pediatr. (2016) 170:1008-19. doi: 10.1001/jamapediatrics.2016.0486

59. Duntas LH, Brenta G. The effect of thyroid disorders on lipid levels and metabolism. Med Clin North Am. (2012) 96:269-81. doi: 10.1016/j.mcna.2012.01.012

60. Brenta G, Fretes O. Dyslipidemias and hypothyroidism. Pediatr Endocrinol Rev. (2014) 11:390-9.

61. Unal E, Akin A, Yildirim R, Demir V, Yildiz I, Haspolat YK. Association of subclinical hypothyroidism with dyslipidemia and increased carotid intimamedia thickness in children. J Clin Res Pediatr Endocrinol. (2017) 9:144-9. doi: $10.4274 /$ jcrpe.3719

62. Marwaha RK, Tandon N, Garg MK, Kanwar R, Sastry A, Narang A, et al. Dyslipidemia in subclinical hypothyroidism in an Indian population. Clin Biochem. (2011) 44:1214-7. doi: 10.1016/j.clinbiochem.2011.07.003

63. Isguven P, Gunduz Y, Kilic M. Effects of thyroid autoimmunity on early atherosclerosis in euthyroid girls with Hashimoto's thyroiditis. J Clin Res Pediatr Endocrinol. (2016) 8:150-6. doi: 10.4274/jcrpe.2145

64. Fazaeli M, Khoshdel A, Shafiepour M, Rohban M. The influence of subclinical hypothyroidism on serum lipid profile, PCSK9 levels and CD36 expression on monocytes. Diabetes Metab Syndr. (2019) 13:312-6. doi: 10.1016/j.dsx.2018.08.021

65. Gaudet D, Langslet G, Gidding SS, Luirink IK, Ruzza A, Kurtz C, et al. Efficacy, safety, and tolerability of evolocumab in pediatric patients with heterozygous familial hypercholesterolemia: rationale and design of the HAUSER-RCT study. J Clin Lipidol. (2018) 12:1199-207. doi: 10.1016/j.jacl.2018.05.007

66. Gojkovic T, Vladimirov S, Spasojevic-Kalimanovska V, Zeljkovic A, Vekic J, Kalimanovska-Ostric D, et al. Can non-cholesterol sterols and lipoprotein subclasses distribution predict different patterns of cholesterol metabolism and statin therapy response? Clin Chem Lab Med. (2017) 55:447-57. doi: 10.1515/cclm-2016-0505

67. Matysik S, Klunemann HH, Schmitz G. Gas chromatography-tandem mass spectrometry method for the simultaneous determination of oxysterols, plant sterols, and cholesterol precursors. Clin Chem. (2012) 58:1557-64. doi: 10.1373/clinchem.2012.189605

68. Gylling H, Korhonen M, Mutanen A, Nissinen MJ, Pakarinen M, Simonen P. Serum non-cholesterol sterols and cholesterol metabolism in childhood and adolescence. Atherosclerosis. (2018) 278:91-6. doi: 10.1016/j.atherosclerosis.2018.09.017

69. Rizzo M, Kotur-Stevuljevic J, Berneis K, Spinas G, Rini GB, Jelic-Ivanovic Z, et al. Atherogenic dyslipidemia and oxidative stress: a new look. Transl Res. (2009) 153:217-23. doi: 10.1016/j.trsl.2009.01.008

70. Faure P, Oziol L, Artur Y, Chomard P. Thyroid hormone (T3) and its acetic derivative (TA3) protect low-density lipoproteins from oxidation by different mechanisms. Biochimie. (2004) 86:411-8. doi: 10.1016/S0300-9084(04)00058-6
71. Bansal SK, Yadav R. A study of the extended lipid profile including oxidized LDL, small dense LDL, lipoprotein (a) and apolipoproteins in the assessment of cardiovascular risk in hypothyroid patients. J Clin Diagn Res. (2016) 10:BC04-8. doi: 10.7860/JCDR/2016/19775.8067

72. Favari E, Thomas MJ, Sorci-Thomas MG. High-density lipoprotein functionality as a new pharmacological target on cardiovascular disease: unifying mechanism that explains high-density lipoprotein protection toward the progression of atherosclerosis. J Cardiovasc Pharmacol. (2018) 71:325-31. doi: 10.1097/FJC.0000000000000573

73. Triolo M, Annema W, Dullaart RP, Tietge UJ. Assessing the functional properties of high-density lipoproteins: an emerging concept in cardiovascular research. Biomark Med. (2013) 7:457-72. doi: $10.2217 / \mathrm{bmm} .13 .35$

74. Rizzo M, Berneis K, Zeljkovic A, Vekic J. Should we routinely measure lowdensity and high-density lipoprotein subclasses? Clin Lab. (2009) 55:421-9.

75. Jung KY, Ahn HY, Han SK, Park YJ, Cho BY, Moon MK. Association between thyroid function and lipid profiles, apolipoproteins, and high-density lipoprotein function. $J$ Clin Lipidol. (2017) 11:1347-53. doi: 10.1016/j.jacl.2017. 08.015

76. Tan KC, Shiu SW, Kung AW. Effect of thyroid dysfunction on highdensity lipoprotein subfraction metabolism: roles of hepatic lipase and cholesteryl ester transfer protein. J Clin Endocrinol Metab. (1998) 83:2921-4. doi: 10.1210/jc.83.8.2921

77. Franco M, Castro G, Romero L, Regalado JC, Medina A, Huesca-Gomez C, et al. Decreased activity of lecithin:cholesterol acyltransferase and hepatic lipase in chronic hypothyroid rats: implications for reverse cholesterol transport. Mol Cell Biochem. (2003) 246:51-6. doi: 10.1023/A:10234518 11547

78. Montecucco F, Favari E, Norata GD, Ronda N, Nofer JR, Vuilleumier N. Impact of systemic inflammation and autoimmune diseases on apoA-I and HDL plasma levels and functions. Handb Exp Pharmacol. (2015) 224:455-82. doi: 10.1007/978-3-319-09665-0_14

79. Kahaly GJ, Hansen MP. Type 1 diabetes associated autoimmunity. Autoimmun Rev. (2016) 15:644-8. doi: 10.1016/j.autrev.2016.02.017

80. Bojanin D, Milenkovic T, Vekic J, Vukovic R, Zeljkovic A, Janac J, et al. Effects of co-existing autoimmune diseases on serum lipids and lipoprotein subclasses profile in paediatric patients with type 1 diabetes mellitus. Clin Biochem. (2018) 54:11-7. doi: 10.1016/j.clinbiochem.2018.01.026

81. Richard-Eaglin A, Smallheer BA. Immunosuppressive/autoimmune disorders. Nurs Clin North Am. (2018) 53:319-34. doi: 10.1016/j.cnur.2018. 04.002

82. de la Llera Moya M, McGillicuddy FC, Hinkle CC, Byrne M, Joshi MR, Nguyen V, et al. Inflammation modulates human HDL composition and function in vivo. Atherosclerosis. (2012) 222:390-4. doi: 10.1016/j.atherosclerosis.2012.02.032

83. Jahangiri A, de Beer MC, Noffsinger V, Tannock LR, Ramaiah C, Webb NR, et al. HDL remodeling during the acute phase response. Arterioscler Thromb Vasc Biol. (2009) 29:261-7. doi: 10.1161/ATVBAHA.108.178681

84. Feingold KR, Grunfeld C. Effect of inflammation on HDL structure and function. Curr Opin Lipidol. (2016) 27:521-30. doi: 10.1097/MOL.0000000000000333

85. Korkmaz H, Tabur S, Ozkaya M, Oguz E, Elboga U, Aksoy N, et al. Paraoxonase and arylesterase levels in autoimmune thyroid diseases. Redox Rep. (2016) 21:227-31. doi: 10.1080/13510002.2015.11 07310

86. Ates I, Altay M, Yilmaz FM, Topcuoglu C, Yilmaz N, Berker D, et al. The impact of levothyroxine sodium treatment on oxidative stress in Hashimoto's thyroiditis. Eur J Endocrinol. (2016) 174:727-34. doi: 10.1530/EJE-15-1061

87. Ruiz M, Frej C, Holmer A, Guo LJ, Tran S, Dahlback B. Highdensity lipoprotein-associated apolipoprotein $\mathrm{M}$ limits endothelial inflammation by delivering sphingosine-1-phosphate to the sphingosine1-phosphate receptor 1. Arterioscler Thromb Vasc Biol. (2017) 37:118-29. doi: 10.1161/ATVBAHA.116.308435

88. Galvani S, Sanson M, Blaho VA, Swendeman SL, Obinata H, Conger H, et al. HDL-bound sphingosine 1-phosphate acts as a biased agonist for the endothelial cell receptor S1P1 to limit vascular inflammation. Sci Signal. (2015) 8:ra79. doi: 10.1126/scisignal.aaa2581 
89. Chi H. Sphingosine-1-phosphate and immune regulation: trafficking and beyond. Trends Pharmacol Sci. (2011) 32:16-24. doi: 10.1016/j.tips.2010.11.002

90. Han C, He X, Xia X, Guo J, Liu A, Liu X, et al. Sphk1/S1P/S1PR1 signaling is involved in the development of autoimmune thyroiditis in patients and NOD.H-2(h4) mice. Thyroid. (2019) 29:700-13. doi: 10.1089/thy.2018.0065

91. Aversa T, Corica D, Zirilli G, Pajno GB, Salzano G, De Luca F, et al. Phenotypic expression of autoimmunity in children with autoimmune thyroid disorders. Front Endocrinol. (2019) 10:476. doi: $10.3389 /$ fendo.2019.00476

92. Semova I, Levenson AE, Krawczyk J, Bullock K, Williams KA, Wadwa RP, et al. Type 1 diabetes is associated with an increase in cholesterol absorption markers but a decrease in cholesterol synthesis markers in a young adult population. J Clin Lipidol. (2019). doi: 10.1016/j.jacl.2019.09.008. [Epub ahead of print].

93. Ganjali S, Dallinga-Thie GM, Simental-Mendia LE, Banach M, Pirro M, Sahebkar A. HDL functionality in type 1 diabetes. Atherosclerosis. (2017) 267:99-109. doi: 10.1016/j.atherosclerosis.2017.10.018

94. Caliskan Z, Demircioglu K, Sayar S, Kahraman R, Caklili O, Ozcan FB, et al. Lipid profile, atherogenic indices, and their relationship with epicardial fat thickness and carotid intima-media thickness in celiac disease. North Clin Istanb. (2019) 6:242-7. doi: 10.14744/nci.2019.54936

95. Salardi S, Maltoni G, Zucchini S, Iafusco D, Zanfardino A, Confetto S, et al. Whole lipid profile and not only HDL cholesterol is impaired in children with coexisting type 1 diabetes and untreated celiac disease. Acta Diabetol. (2017) 54:889-94. doi: 10.1007/s00592-017-1019-5

96. Jessup AB, Law JR, Spagnoli A. Are HDL levels lower in children with type 1 diabetes and concurrent celiac disease compared with children with type 1 diabetes only? J Pediatr Endocrinol Metab. (2014) 27:1213-6. doi: 10.1515/jpem-2013-0464

97. Monzani F, Caraccio N, Kozakowa M, Dardano A, Vittone F, Virdis A, et al. Effect of levothyroxine replacement on lipid profile and intima-media thickness in subclinical hypothyroidism: a double-blind, placebo- controlled study. J Clin Endocrinol Metab. (2004) 89:2099-106. doi: 10.1210/jc.2003-031669

98. Villar HC, Saconato H, Valente O, Atallah AN. Thyroid hormone replacement for subclinical hypothyroidism. Cochrane Database Syst Rev. (2007) CD003419. doi: 10.1002/14651858.CD003419.pub2

99. Razvi S, Ingoe L, Keeka G, Oates C, McMillan C, Weaver JU. The beneficial effect of L-thyroxine on cardiovascular risk factors, endothelial function, and quality of life in subclinical hypothyroidism: randomized, crossover trial. $J$ Clin Endocrinol Metab. (2007) 92:1715-23. doi: 10.1210/jc.2006-1869

100. Meier C, Staub JJ, Roth CB, Guglielmetti M, Kunz M, Miserez AR, et al. TSH-controlled L-thyroxine therapy reduces cholesterol levels and clinical symptoms in subclinical hypothyroidism: a double blind, placebo-controlled trial (Basel Thyroid Study). J Clin Endocrinol Metab. (2001) 86:4860-6. doi: $10.1210 /$ jcem. 86.10 .7973

101. Caraccio N, Ferrannini E, Monzani F. Lipoprotein profile in subclinical hypothyroidism: response to levothyroxine replacement, a randomized placebo-controlled study. J Clin Endocrinol Metab. (2002) 87:1533-8. doi: $10.1210 /$ jcem.87.4.8378

102. Li X, Wang Y, Guan Q, Zhao J, Gao L. The lipid-lowering effect of levothyroxine in patients with subclinical hypothyroidism: a systematic review and meta-analysis of randomized controlled trials. Clin Endocrinol. (2017) 87:1-9. doi: 10.1111/cen.13338

103. Minarikova Z, Gaspar L, Kruzliak P, Celecova Z, Oravec S. The effects of treatment on lipoprotein subfractions evaluated by polyacrylamide gel electrophoresis in patients with autoimmune hypothyroidism and hyperthyroidism. Lipids Health Dis. (2014) 13:158. doi: 10.1186/1476-511X-13-158

104. Krysiak R, Okopien B. The effect of levothyroxine and selenomethionine on lymphocyte and monocyte cytokine release in women with Hashimoto's thyroiditis. J Clin Endocrinol Metab. (2011) 96:2206-15. doi: 10.1210/jc.2010-2986

105. Schmidt M, Voell M, Rahlff I, Dietlein M, Kobe C, Faust M, et al. Long-term follow-up of antithyroid peroxidase antibodies in patients with chronic autoimmune thyroiditis (Hashimoto's thyroiditis) treated with levothyroxine. Thyroid. (2008) 18:755-60. doi: 10.1089/thy.2008.0008
106. Korzeniowska K, Ramotowska A, Szypowska A, Szadkowska A, Fendler W, Kalina-Faska B, et al. How does autoimmune thyroiditis in children with type 1 diabetes mellitus influence glycemic control, lipid profile and thyroid volume? J Pediatr Endocrinol Metab. (2015) 28:275-8. doi: 10.1515/jpem-2013-0455

107. Mazaheri T, Sharifi F, Kamali K. Insulin resistance in hypothyroid patients under Levothyroxine therapy: a comparison between those with and without thyroid autoimmunity. J Diabetes Metab Disord. (2014) 13:103. doi: 10.1186/s40200-014-0103-4

108. Monzani A, Prodam F, Rapa A, Moia S, Agarla V, Bellone S, et al. Endocrine disorders in childhood and adolescence. Natural history of subclinical hypothyroidism in children and adolescents and potential effects of replacement therapy: a review. Eur J Endocrinol. (2013) 168:R1-R11. doi: 10.1530/EJE-12-0656

109. Radetti G, Maselli M, Buzi F, Corrias A, Mussa A, Cambiaso P, et al. The natural history of the normal/mild elevated TSH serum levels in children and adolescents with Hashimoto's thyroiditis and isolated hyperthyrotropinaemia: a 3-year follow-up. Clin Endocrinol. (2012) 76:3948. doi: $10.1111 / \mathrm{j} .1365-2265.2011 .04251 . x$

110. Wasniewska M, Salerno M, Cassio A, Corrias A, Aversa T, Zirilli G, et al. Prospective evaluation of the natural course of idiopathic subclinical hypothyroidism in childhood and adolescence. Eur J Endocrinol. (2009) 160:417-21. doi: 10.1530/EJE-08-0625

111. Wasniewska M, Corrias A, Aversa T, Valenzise M, Mussa A, De Martino $\mathrm{L}$, et al. Comparative evaluation of therapy with L-thyroxine versus no treatment in children with idiopathic and mild subclinical hypothyroidism. Horm Res Paediatr. (2012) 77:376-81. doi: 10.1159/000339156

112. Catli G, Kir M, Anik A, Yilmaz N, Bober E, Abaci A. The effect of L-thyroxine treatment on left ventricular functions in children with subclinical hypothyroidism. Arch Dis Child. (2015) 100:130-7. doi: 10.1136/archdischild-2014-306381

113. de Souza RJ, Mente A, Maroleanu A, Cozma AI, Ha V, Kishibe T, et al. Intake of saturated and trans unsaturated fatty acids and risk of all cause mortality, cardiovascular disease, and type 2 diabetes: systematic review and meta-analysis of observational studies. BMJ. (2015) 351:h3978. doi: 10.1136/bmj.h3978

114. Ramsden CE, Zamora D, Majchrzak-Hong S, Faurot KR, Broste SK, Frantz $\mathrm{RP}$, et al. Re-evaluation of the traditional diet-heart hypothesis: analysis of recovered data from Minnesota Coronary Experiment (1968-73). BMJ. (2016) 353:11246. doi: 10.1136/bmj.i1246

115. Harcombe Z, Baker JS, Cooper SM, Davies B, Sculthorpe N, DiNicolantonio $\mathrm{JJ}$, et al. Evidence from randomised controlled trials did not support the introduction of dietary fat guidelines in 1977 and 1983: a systematic review and meta-analysis. Open Heart. (2015) 2:e000196. doi: 10.1136/openhrt-2014-000196

116. Ference BA, Ginsberg HN, Graham I, Ray KK, Packard CJ, Bruckert E, et al. Low-density lipoproteins cause atherosclerotic cardiovascular disease. 1. Evidence from genetic, epidemiologic, and clinical studies. A consensus statement from the European Atherosclerosis Society Consensus Panel. Eur Heart J. (2017) 38:2459-72. doi: 10.1093/eurheartj/ehx144

117. Langlois MR, Chapman MJ, Cobbaert C, Mora S, Remaley AT, Ros E, et al. Quantifying atherogenic lipoproteins: current and future challenges in the era of personalized medicine and very low concentrations of LDL cholesterol. A consensus statement from EAS and EFLM. Clin Chem. (2018) 64:1006-33. doi: $10.1373 /$ clinchem.2018.287037

118. Bojanin D, Vekic J, Milenkovic T, Vukovic R, Zeljkovic A, Stefanovic A, et al. Association between proprotein convertase subtilisin/kexin 9 (PCSK9) and lipoprotein subclasses in children with type 1 diabetes mellitus: effects of glycemic control. Atherosclerosis. (2019) 280:14-20. doi: 10.1016/j.atherosclerosis.2018.11.020

119. Lazarus J, Brown RS, Daumerie C, Hubalewska-Dydejczyk A, Negro R, Vaidya B. 2014 European thyroid association guidelines for the management of subclinical hypothyroidism in pregnancy and in children. Eur Thyroid J. (2014) 3:76-94. doi: 10.1159/000362597

120. Kapelari K, Kirchlechner C, Hogler W, Schweitzer K, Virgolini I, Moncayo R. Pediatric reference intervals for thyroid hormone levels from birth to adulthood: a retrospective study. BMC Endocr Disord. (2008) 8:15. doi: $10.1186 / 1472-6823-8-15$ 
121. Chaler EA, Fiorenzano R, Chilelli C, Llinares V, Areny G, Herzovich V, et al. Age-specific thyroid hormone and thyrotropin reference intervals for a pediatric and adolescent population. Clin Chem Lab Med. (2012) 50:885-90. doi: 10.1515/cclm-2011-0495

122. Elmlinger MW, Kuhnel W, Lambrecht HG, Ranke MB. Reference intervals from birth to adulthood for serum thyroxine (T4), triiodothyronine (T3), free T3, free T4, thyroxine binding globulin (TBG) and thyrotropin (TSH). Clin Chem Lab Med. (2001) 39:973-9. doi: 10.1515/CCLM.2001.158

123. Onsesveren I, Barjaktarovic M, Chaker L, de Rijke YB, Jaddoe VWV, van Santen HM, et al. Childhood thyroid function reference ranges and determinants: a literature overview and a prospective cohort study. Thyroid. (2017) 27:1360-9. doi: 10.1089/thy.2017.0262

124. Baloch Z, Carayon P, Conte-Devolx B, Demers LM, Feldt-Rasmussen U, Henry JF, et al. Laboratory medicine practice guidelines. Laboratory support for the diagnosis and monitoring of thyroid disease. Thyroid. (2003) 13:3126. doi: $10.1089 / 105072503321086962$
125. Gullu S, Emral R, Bastemir M, Parkes AB, Lazarus JH. In vivo and in vitro effects of statins on lymphocytes in patients with Hashimoto's thyroiditis. Eur J Endocrinol. (2005) 153:41-8. doi: 10.1530/eje.1. 01941

Conflict of Interest: The authors declare that the research was conducted in the absence of any commercial or financial relationships that could be construed as a potential conflict of interest.

Copyright (c) 2019 Vukovic, Zeljkovic, Bufan, Spasojevic-Kalimanovska, Milenkovic and Vekic. This is an open-access article distributed under the terms of the Creative Commons Attribution License (CC BY). The use, distribution or reproduction in other forums is permitted, provided the original author(s) and the copyright owner(s) are credited and that the original publication in this journal is cited, in accordance with accepted academic practice. No use, distribution or reproduction is permitted which does not comply with these terms. 